\title{
Modeling Human Viral Diseases: Trials and Triumphs
}

\author{
Velpandi Ayyavoo* \\ Department of Infectious Diseases and Microbiology, Graduate School of Public Health, University of Pittsburgh, Pittsburgh, \\ $P A$, United States
}

Keywords: viral replication, viral pathogenesis, modeling, animal models, in vitro cell culture model

OPEN ACCESS

Edited by:

Akio Adachi,

Kansai Medical University, Japan

Reviewed by:

Martina Kovarova,

University of North Carolina at Chapel Hill, United States

Mark Zanin,

First Affiliated Hospital of Guangzhou Medical University, China

*Correspondence: Velpandi Ayyavoo velpandi@pitt.edu

Specialty section:

This article was submitted to Modeling of Viral Replication and Pathogenesis,

a section of the journal Frontiers in Virology

Received: 08 June 2021

Accepted: 21 July 2021

Published: 24 August 2021

Citation:

Ayyavoo V (2021) Modeling Human Viral Diseases: Trials and Triumphs.

Front. Virol. 1:722297.

doi: 10.3389/fviro.2021.722297
Understanding and studying human diseases caused by pathogens require tools other than the natural host, as many diseases are lethal to humans. To understand the mechanism(s) involved in pathogenesis caused either by genetics or microbes including viruses, it is important to have model systems where disease can be induced by altering genes or host-pathogen interactions and where the functional consequences can be monitored closely. Among the human pathogens, viruses are known to cause debilitating outbreaks resulting in significant morbidity and mortality due to the emerging and/or reemerging outbreaks (1-3). Many virus species are associated with human diseases ranging from hemorrhagic, gastroenteric, pharyngeal to neuroinvasion (4-10). Thus, understanding the virus biology and their ability to establish infection and induce pathogenesis in human host remains a priority. However, studying pathogenic viruses require appropriate host species other than humans to model diseases development and progression. For centuries, researchers have used animal models inoculated with viruses for the purpose of monitoring and manipulating disease progression. In this way, animal models have contributed significantly to not only understanding disease development, but also to defining vaccine efficacy, and to drug and treatment development (11-14). However, the availability of larger animals (both inbreed and out breed), cost and ethical concerns pushed the field to identify alternate model systems to study virushost interactions. More recently, 2D cell culture and 3D organoid models have become increasingly prominent and refined disease models for dissecting the molecular mechanisms underlying viral induced pathogenesis (14-17). Each model has strengths and weaknesses and understanding how these relate to disease phenotypes is key to interpreting the results obtained from these systems.

\section{ANIMAL MODELS FOR VIRAL DISEASES}

One of the most common approaches to study virus infection and the associated disease development is to use small and large animal models that recapitulate human diseases. For example, studies on virus-host interaction and pathogenesis were modeled using rodent, rabbits, dogs, horses, Ferrets, and non-human (18-22). The major advantage of using the animal model is the presence of immune system which mimics the effect of immune response during disease development. Furthermore, in some animal models the immune system could be manipulated in ways that makes it possible to ascertain the contribution of specific immune components to disease outcome $(23,24)$. Mice, rats, Ferrets and non-human primates are also used to study pathogenesis induced by viruses, bacteria, and parasites as well as in vaccine efficacy studies $(22,25-27)$, but cross-model interpretations are limited by the fact that these animal models may not represent similar disease pathogenesis due to inter species variation and genetic background. For instance, requirements of species-specific entry receptors for HBV, SARS-CoV-2, HIV, and other process are key for infection and disease development $(28,29)$. Additionally, animal models are oftentimes infected with a species-specific counter part of a human pathogen (e.g., SIV vs. HIV) that corresponds to the receptors and proteins necessary for transmission and disease development 
in that host. These differences in physiology necessitated the development of transgenic animals with human specific cell types that will serve as target cell for human pathogens with appropriate receptors $(23,24)$. Significant progress has been made in this area of research; however, there are several restrictions, including the presence of species specific innate immune factors that hampered the infection, spread, and transmission within these animals (21, 30). More importantly, the downstream and secondary effects caused by viruses, viral proteins and its byproducts can't be fully studied using these models. Additionally, animal models, either small or large, are expensive, labor intensive, and subject to the consideration of ethical issues, especially for work involving non-human primates and humanized mice.

\section{IN VITRO CELL CULTURE MODEL TO STUDY VIRAL INFECTION}

Cell culture models have become increasingly valuable research tools and studies using 2D single cell lineages infected with pathogens have significantly expanded our understanding the biology of pathogens. For example, single cell-based culture models provided a unique opportunity to study how viruses (HCV, hemorrhagic fever viruses, HIV) induce cellular dysregulation and pathogenic effects in specific cell types (16, 17, 31). Specific studies using primary cell based 2D cultures offered a great avenue to understand the changes at the cellular level and more precisely at the cellular level (17). These studies furthered our attempts to identify the specific target cell types involved in disease development, the requirements of cellspecific receptors, gene control, and the ability of pathogens to manipulate host cellular genes and signaling pathways. However, in the body, cells function as part of a network of cells and a lack of holistic to integrate additional cells in 2D cultures, including other cell types within a specific organ, reduce the physiologic relevance and significance of this system. Additionally, the innate defense responses induced by other cell types in the surrounding microenvironment is lacking in $2 \mathrm{D}$ cell culture models. Thus, developing 3D organoid models that mimic in vivo conditions for studying normal development and

\section{REFERENCES}

1. Khan MA, Bass DM. Viral infections: new and emerging. Curr Opin Gastroenterol. (2010) 26:26-30. doi: 10.1097/MOG.0b013e328333d7af

2. Graham BS, Sullivan NJ. Emerging viral diseases from a vaccinology perspective: preparing for the next pandemic. Nat Immunol. (2018) 19:20-8. doi: 10.1038/s41590-0170007-9

3. Sagaya Jansi R, Khusro A, Agastian P, Alfarhan A, Al-Dhabi NA, Arasu MV, et al. Emerging paradigms of viral diseases and paramount role of natural resources as antiviral agents. Sci Total Environ. (2021) 759:143539. doi: 10.1016/j.scitotenv.2020.143539

4. Robilotti E, Deresinski S, Pinsky BA. Norovirus. Clin Microbiol Rev. (2015) 28:134-64. doi: 10.1128/CMR.00075-14 differentiation and disease pathologies has become a priority. Several approaches have been taken to create these models ranging from co-culturing multiple cells within a tissue culture well to development of 3D organoids that represent different organ systems to study respiratory and neurotropic viruses (26, 32, 33).

Organoids using supporting materials such as Matrigel and other scaffolding elements lead to $3 \mathrm{D}$ organoids where cells differentiate and mature into various cell types within a specific organ. Several 3D organoid models have been successfully established including models of brain and/or cerebral, intestine/colon and retina. Importantly, 3D organoids have great potential for modeling viral diseases including Zika, Influenza, HIV-, and others $(34,35)$. More recently organ specific human tissues and tissue-based organoids (lung, heart, and brain) are used to study influenza, SARS-CoV-2, Zika, and Dengue virus infection and pathogenesis (36-38). Though the organoid and tissue models provide a great in vitro alternate model that is quick and in expensive, there are certain limitations associated with them as well. For instance, maintaining these cultures for a longer period to study chronic viral diseases is an issue. This is due to lack vascularization in this model, that will prevent the flow of nutrients to the core region of the 3D-organoid structures.

Studying host-pathogen including infectious viruses that cause morbidity and mortality in humans is a challenging and constantly evolving area of research. The recent emergence and reemergence of pathogenic viruses force the scientific community to find alternate in vitro and in vivo systems that will provide a suitable platform to model viral pathogenesis and disease development. As indicated above, there are several models that have both pros and cons, however, a great deal of progress has been made to model several viral diseases. With constant addition and/or reinvention, these models can be tweaked to mimic physiological relevance of the host, that will help us to study viral diseases and develop therapeutics and vaccines.

\section{AUTHOR CONTRIBUTIONS}

The author confirms being the sole contributor of this work and has approved it for publication.
5. Goeijenbier M, van Wissen M, van de Weg C, Jong E, Gerdes VE, Meijers JC, et al. Review: Viral infections and mechanisms of thrombosis and bleeding. $J$ Med Virol. (2012) 84:1680-96. doi: 10.1002/jmv.23354

6. Esona MD, Gautam R. Rotavirus. Clin Lab Med. (2015) 35:36391. doi: 10.1016/j.cll.2015.02.012

7. Baseler L, Chertow DS, Johnson KM, Feldmann H, Morens DM. The pathogenesis of ebola virus disease. Annu Rev Pathol. (2017) 12:387-418. doi: 10.1146/annurev-pathol-052016-10 0506

8. Montalvan V, Lee J, Bueso T, Toledo JDe, Rivas K. Neurological manifestations of COVID-19 and other coronavirus infections: A systematic review. Clin Neurol Neurosurg. (2020) 194:105921. doi: 10.1016/j.clineuro.2020.105921

9. Banerjee, Tripathi A. Recent advances in understanding Japanese encephalitis. F1000Res. (2019) 8:F1000. doi: 10.12688/f1000research.19693.1 
10. Zayyad Z, Spudich S. Neuropathogenesis of HIV: from initial neuroinvasion to HIV-associated neurocognitive disorder (HAND). Curr HIV/AIDS Rep. (2015) 12:16-24. doi: 10.1007/s11904-014-0255-3

11. Sestak K. Non-human primate models of enteric viral infections. Viruses. (2018) 10:544. doi: 10.20944/preprints201808.0438.v1

12. Yuan L, Tang Q, Cheng T, Xia N. Animal models for emerging coronavirus: progress and new insights. Emerg Microbes Infect. (2020) 9:94961. doi: 10.1080/22221751.2020.1764871

13. Reynolds P, Marzi A. Ebola and Marburg virus vaccines. Virus Genes. (2017) 53:501-15. doi: 10.1007/s11262-017-1455-x

14. Hu J, Lin YY, Chen PJ, Watashi K, Wakita T. Cell and animal models for studying hepatitis b virus infection and drug development. Gastroenterology. (2019) 156:338-54. doi: 10.1053/j.gastro.2018.06.093

15. Liu X, Mondal AM. Conditional cell reprogramming for modeling hostvirus interactions and human viral diseases. J Med Virol. (2020) 92:244052. doi: 10.1002/jmv.26093

16. Castro V, Ávila-Pérez G, Mingorance L, Gastaminza P. A cell culture model for persistent HCV infection. Methods Mol Biol. (2019) 1911:15768. doi: 10.1007/978-1-4939-8976-8_10

17. Djavani M. A primary human liver cell culture model for hemorrhagic fever viruses. Methods Mol Biol. (2018) 1604:291302. doi: 10.1007/978-1-4939-6981-4_23

18. Siragam V, Wong G, Qiu XG. Animal models for filovirus infections. Zool Res. (2018) 39:15-24. doi: 10.24272/j.issn.2095-8137.2017.053

19. Wu YH, Tseng CK, Lin CK, Wei CK, Lee JC, Young KC. ICR suckling mouse model of Zika virus infection for disease modeling and drug validation. PLoS Negl Trop Dis. (2018) 12:e0006848. doi: 10.1371/journal.pntd.0006848

20. Wong J, Layton D, Wheatley AK, Kent SJ. Improving immunological insights into the ferret model of human viral infectious disease. Influenza Other Respir Viruses. (2019) 13:535-46. doi: 10.1111/irv.12687

21. Mifsud EJ, Tai CM, Hurt AC. Animal models used to assess influenza antivirals. Expert Opin Drug Discov. (2018) 13:11319. doi: 10.1080/17460441.2018.1540586

22. Shi J, Wen Z, Zhong G, Yang H, Wang C, Huang B, et al. Susceptibility of ferrets, cats, dogs, and other domesticated animals to SARS-coronavirus 2. Science. (2020) 368:1016-20. doi: 10.1126/science.abb7015

23. Tao L, Reese TA. Making mouse models that reflect human immune responses. Trends Immunol. (2017) 38:181-93. doi: 10.1016/j.it.2016.12.007

24. Tyagi RK, Li J, Jacobse J, Snapper SB, Shouval DS, Goettel JA. Humanized mouse models of genetic immune disorders and hematological malignancies. Biochem Pharmacol. (2020) 174:113671. doi: 10.1016/j.bcp.2019.113671

25. Dey TK, Karmakar BC, Sarkar A, Paul S, Mukhopadhyay AK. A mouse model of helicobacter pylori infection. Methods Mol Biol. (2021) 2283:13151. doi: 10.1007/978-1-0716-1302-3_14

26. Barron SL, Saez J, Owens RM. In vitro models for studying respiratory host-pathogen interactions. Adv Biol (Weinh). (2021) 5:e2000624. doi: 10.1002/adbi.202000624

27. Schlottau K, Rissmann M, Graaf A, Schön J, Sehl J, Wylezich C, et al. SARSCoV-2 in fruit bats, ferrets, pigs, and chickens: an experimental transmission study. Lancet Microbe. (2020) 1:e218-25. doi: 10.1016/S2666-5247(20)30089-6
28. Wettengel JM, Burwitz BJ. Innovative HBV animal models based on the entry receptor NTCP. Viruses. (2020) 12:828. doi: 10.3390/v120 80828

29. Yang XH, Deng W, Tong Z, Liu YX, Zhang LF, Zhu H, et al. Mice transgenic for human angiotensin-converting enzyme 2 provide a model for SARS coronavirus infection. Comp Med. (2007) 57:450-9.

30. Stolp B, Melican K. Microbial pathogenesis revealed by intravital microscopy: pros, cons and cautions. FEBS Lett. (2016) 590:201426. doi: $10.1002 / 1873-3468.12122$

31. Whitney JB, Brad Jones R. In vitro and in vivo models of HIV latency. Adv Exp Med Biol. (2018) 1075:241-63. doi: 10.1007/978-981-13-0484-2_10

32. Antonucci J, Gehrke L. Cerebral organoid models for neurotropic viruses. ACS Infect Dis. (2019) 5:1976-9. doi: 10.1021/acsinfecdis.9b00339

33. Hocke AC, Suttorp N, Hippenstiel S. Human lung ex vivo infection models. Cell Tissue Res. (2017) 367:511-24. doi: 10.1007/s00441-016-2546-Z

34. Ramani S, Crawford SE, Blutt SE, Estes MK. Human organoid cultures: transformative new tools for human virus studies. Curr Opin Virol. (2018) 29:79-86. doi: 10.1016/j.coviro.2018.04.001

35. Li Y, Wu Q, Sun $\mathrm{X}$, Shen J, Chen H. Organoids as a powerful model for respiratory diseases. Stem Cells Int. (2020) 2020:5847876. doi: 10.1155/2020/5847876

36. Zmora P, Molau-Blazejewska P, Bertram S, Walendy-Gnirß K, Nehlmeier I, Hartleib A, et al. Non-human primate orthologues of TMPRSS2 cleave and activate the influenza virus hemagglutinin. PLoS ONE. (2017) 12:e0176597. doi: 10.1371/journal.pone.0176597

37. Bojkova D, Wagner JUG, Shumliakivska M, Aslan GS, Saleem $\mathrm{U}$, Hansen A, et al. SARS-CoV-2 infects and induces cytotoxic effects in human cardiomyocytes. Cardiovasc Res. (2020) 116:220715. doi: $10.1093 / \mathrm{cvr} / \mathrm{cvaa} 267$

38. Castanha PMS, Erdos G, Watkins SC, Falo LD Jr, Marques ETA, Barratt-Boyes SM. Reciprocal immune enhancement of dengue and Zika virus infection in human skin. JCI Insight. (2020) 5. doi: 10.1172/jci.insight.133653

Conflict of Interest: The author declares that the research was conducted in the absence of any commercial or financial relationships that could be construed as a potential conflict of interest.

Publisher's Note: All claims expressed in this article are solely those of the authors and do not necessarily represent those of their affiliated organizations, or those of the publisher, the editors and the reviewers. Any product that may be evaluated in this article, or claim that may be made by its manufacturer, is not guaranteed or endorsed by the publisher.

Copyright (๑) 2021 Ayyavoo. This is an open-access article distributed under the terms of the Creative Commons Attribution License (CC BY). The use, distribution or reproduction in other forums is permitted, provided the original author $(s)$ and the copyright owner(s) are credited and that the original publication in this journal is cited, in accordance with accepted academic practice. No use, distribution or reproduction is permitted which does not comply with these terms. 